\title{
Students Demotivating Factors in the EFL classroom: The Case of Morocco
}

\author{
Youssef BABA KHOUYA* \\ Department of Education, Inje University, Gimhae. South Korea \\ Corresponding Author: Youssef BABA KHOUYA, E-mail: babakhouya84@gmail.com
}

\section{ARTICLE INFO}

Article history

Received: December 20, 2017

Accepted: March 12, 2018

Published: April 30, 2018

Volume: 9 Issue: 2

Advance access: March 2018

Conflicts of interest: None

Funding: None

\section{Key words:}

Demotivation,

Demotivating Factors,

English Language Learning,

English Language Teaching,

Foreign Language,

Second Language

\begin{abstract}
This study was conducted to investigate the problem of demotivation in English language learning (ELL) within the Moroccan context. To attain this objective, two instruments were adopted: a questionnaire and a writing test. The participants involved in this study were 201 baccalaureate students (second year) from six secondary schools, 84 were males and 117 were females. The data gathered was quantitatively analyzed through frequency distribution and percentages, Cross-tabulation, Chi-Square Tests, Independent Samples t-Test, in addition to the statistical significance which was set at the level of .05 (95\%) for all statistical procedures. Six main findings were reported: (1) students positively perceived themselves in ELL; (2) students did not consider English language as a demotivating factor while learning it itself; (3) students were largely positive towards their teachers of English; (4) crowded classrooms were the main demotivators in learning environment among classmates, textbook of English, and classroom atmosphere; (5) generally, learning environment was the main demotivating factor in ELL; (6) as for gender, there was no significant difference between males and females in terms of the number of demotivating factors that they encountered. In the light of these findings, some pertinent implications were provided.
\end{abstract}

\section{INTRODUCTION}

For a clear understanding of what demotivation is, defining the opposite term, motivation, would clarify it more precisely. Gardner (1985) defined second language (L2) motivation as "the extent to which the individual works or strives to learn the language because of a desire to do so and the satisfaction experienced in this activity." Accordingly, motivation is based on some elements that turn on the desire of learners and stimulate them to learn a language.

Gardner (1985) also stated that motivation is distinguished into two types: instrumental motivation, which is a desire that is based on a function or a job to be obtained by learning that language; for example, a student may be motivated to learn English language in order to be a teacher or a translator; the second type of motivation is called integrative motivation, it is a situation in which a student wants to learn a language for the sake of integrating and being a part of the society where that language is used; for instance, an immigrant may want to learn the French language to communicate with the French community he/she lives in. Having constructed a clear idea about what motivation is will make the understanding of demotivation, the core of this study, easy to comprehend.

Demotivation is a situation that causes a lot of problems during the process of learning a language, and it may lead the learner to a complete rejection. A famous psycholinguist who dealt with this issue was Dörnyei. He defined demotivation as "specific external forces that reduce or diminish the motivational basis of a behavioral intention or ongoing action" (2001). Clearly, any factor or element which contributes to decreasing the motivational level in the learner is considered a demotivator. Besides, Dörnyei argues that "being demotivated does not necessarily mean that all the positive influences that originally made up the motivational basis of a behavior have been annulled; rather, it is only the resultant force that has been depended by a strong negative component, while some other positive motives may still remain operational" (2005) This signifies that a demotivated learner is not inevitably a learner who does not have any motives in learning a language, but the rate of demotivation is higher compared to motivation. That is to say, the demotivating factors outperform the motivating ones. Hence, the demotivation level differs from one learner to another; as there are high and low motivated students, there are also high and low demotivated students, the range goes from diminished motivation to total loss of motivation.

Deci and Ryan (1985) came up with another term to be compared with demotivation, namely amotivation. They claimed that amotivation is not an absolute absence of 
motivation which may be due to an initial interest, but due to the learner's experience of a situation in which he/she feels incompetent and unable to learn that language. To put it simply, both of demotivation and amotivation refer to lack of motivation, but the former concerns external factors while the latter means general outcome expectations that are unrealistic for one reason or another.

With regard to the current study, it was conducted in order to investigate the problem of demotivation in ELL among Moroccan students. Accordingly, this study addressed the following six research questions:

1. Do students perceive themselves positively in ELL?

2. Do students regard English as a demotivator?

3. Do students have a positive attitude towards their teachers of English?

4. Are crowded classrooms the main demotivators in learning environment?

5. What is the main demotivating factor in ELL?

6. Is there a significant difference in the perceived frequency of demotivators among males and females?

\section{LITERATURE REVIEW}

\section{Demotivation and L2 Learning}

\section{Chambers (1993)}

In 1993, chambers made an attempt to find some solutions and answers that may help students to get rid of their demotivational behavior towards foreign language learning (FLL). Accordingly, he conducted a study in which he included four Leeds schools and administered questionnaires to 191 year nine pupils in eight classes, along with seven teachers who were asked to fill out the questionnaire as well. What makes chambers' (1993) study have a strong credibility is gathering data from two types of participants, namely students and teachers so as to get opinions from the two opposite sides.

As a result of this study, six teachers out of seven attribute many demotivational behaviors to students "poor concentration; lack of belief in own capabilities; no effort made to learn; 'What's the use?' syndrome; negative or nil response to praise; lethargy; lack of cooperation; disruptive; distracted; distracts other pupils; throws things; shouts out; produces little or no homework; fails to bring materials to lessons; claims to have lost materials." (Chambers, 1993)

The way those teachers describe their demotivated students seems to be biased, because they totally attribute demotivation to students, and no one of the seven teachers mentions him/herself as a demotivator. In other words, this shows that the majority of teachers do not view themselves as contributors to students' demotivation. Furthermore, those teachers conclude that the nature of demotivation is psychological, attitudinal, social, historical, and geographical. Some of those causes are, for example, forcing students to choose a language course, giving no interest to language, and language is not a priority. Additionally, only one teacher out of seven relates demotivation to social context which needs to be taken into serious consideration not only by teachers, but by parents and society as well.
Accordingly, teachers need to be equipped with several skills accompanied with language skills. This should serve as an indication that language teachers should be able to detect demotivated students and try to eradicate those demotivating factors by, for instance, encouraging their students to learn language and making lessons more enjoyable and lively. This will certainly put students in a good context and mood that can change their views towards FLL.

Nevertheless, Chambers' (1993) main focus was precisely directed towards pupil's view on language learning. Most of the 191 pupils claim that learning a language is very important or quite important, which implies that they are aware of the significance of FLL in their lives, but they do not consider it an enjoyable process "only about $10 \%$ express any kind of pleasure, about $50 \%$ do not mind and the remainder either do not enjoy it or loathe it" (Chambers, 1993). Moreover, Chambers (1993) reported that among the four language skills, listening was classified as the least popular one due to the fact that "pupils complain of unclear recordings, defective equipment, foreigners speaking too fast and inappropriate exploitation of material... it is seen as a test rather than a learning experience." On the contrary, the pupils point out that speaking is enjoyed even though many of them view it embarrassing, because they do not want to be laughed at or pocked at if they make a mistake. For shy and reserved students, writing is the most desired skill as it is an opportunity not to be asked by the teacher and to keep away from embarrassment, whereas only a minority considers writing as a useless skill. Reading skill is given less importance because the pupils state that reading texts that are not understood is nonsense. Classroom is not important for most of the pupils, but some of them criticize class-size as an important element of language learning, they mention that they cannot learn German as the classroom is crowded, and that they need a large classroom and two teachers. Other students come to classroom with attitudes brought from home or with unsuccessful experience with another language or with low self-esteem.

Chambers (1993) concluded his study by stating that it is beyond the teacher ability to satisfy all his students, this goal is far reached. Besides, he drew some points which are as follows:

- Students do not have similar interests and needs which make it hard to satisfy all of them;

- demotivated pupils refuse to be neglected by their teacher, they, pupils, have to be backed up and given help;

- low self-esteem is usually associated with demotivated pupils;

- $\quad$ taking pupils' opinions is of pivotal significance; and

- the surrounding of pupils including attitudes of parents, friends, and society should be given a close attention.

Over all, what can be drawn from this study is that demotivation is a complicated problem that many foreign language (FL) learners suffer from, and it is caused by several factors such as teacher, low self-esteem, and unsuccessful experience with learning a language. The goal that Chambers (1993) aimed at in his study was to find some solutions that may help both students and teachers to get rid of, or at least reduce, this negative issue that can deprive learners from learning an FL. 


\section{Ushioda (1998)}

In a qualitative study that was carried out by Ushioda (1998), she involved 20 Irish learners of French at Trinity College, Dublin. Ushioda (1998) aimed at identifying the demotivators that those students experienced while learning that FL. Ushioda (1998) claimed that those demotivators, almost without exception, were pertained to negative aspects of the institutionalized context including particular language teaching methods, learning tasks, and course work pressures.

Ushioda's (1998) study took place in two periods: the first period was in 1991, and data was collected via loosely structured interview for identifying the factors that motivated students to learn French. It was revealed that the students referred to the most significant factors earlier and less significant ones later in the interviews. Accordingly, Ushioda (1998) discovered eight motivational dimensions, namely academic interest, language-related enjoyment/liking, desired levels of L2 competence, personal goals, positive learning history, personal satisfaction, feelings about French-speaking countries or people, and external pressures/ incentives. Language related enjoyment/liking and positive learning history were ranked first as motivational factors, followed by personal goals and desired levels of FL competence. Moreover, a negative correlation was revealed between French grade and personal goals, while a positive correlation was found between positive learning history and desired levels of FL.

The second period of Ushioda's (1998) study was carried out in 1993 via a more structured interview which contained open-ended questions, which allowed her to examine particular types of motivational experience and their development through time. Besides, the structured interview directed its focus towards four areas which are as follows:

The first area of motivation was called motivational evolution over time. Ushioda (1998) found two types of changes which were divided into global and qualitative. The former is concerned with the change regarding the level of motivation, which improves, sometimes, as a result of coursework and exams or having a good relationship with a speaker of an FL. On the contrary, some coursework are also responsible for lessening students' motivation resulting from their dissatisfaction toward them. This implies that high motivation is associated with positive FL experience and vice versa. Concerning the qualitative changes, Ushioda (1998) found many factors, which were categorized later into three classes by Hirvonen (2010) "qualitative developments such as development of intrinsic motivation through a positive L2 experience in France, overriding short term incentives such as high motivation from immediate exam pressure, and clearer definition of L2 related personal goals such as entering teaching profession."

The second area of motivation that was dealt with by Ushioda (1998) in the interview was motivational perspectives on the L2 development over time. It was revealed that the participants who gave importance to positive learning history believed motivationally significant to improve their L2/FL. Doing well in L2 (French) provided the students with more satisfaction and self-confidence, otherwise they would feel ashamed if they did not develop in French. This development was measured via, for example, exam performance. On the contrary, the participants who answered that they did not regard doing well in the L2 to be an important motivating factor put heavy emphasis on incentive, such as spending the following academic year in France. Additionally, Ushioda (1998) pointed out that internal factors contributed more to success in French, including personal abilities and interest in the L2, while external factors had less contribution to students' success in the L2, teachers as a case in point.

In the third question included in the interview, factors negatively affecting L2 motivation, Ushioda (1998) tried to identify the factors responsible for demotivating L2 students. That is to say, the factors that negatively affect L2 motivation, she found that external factors over exceeded internal ones. As illustrations for external demotivating factors, Ushioda (1998) mentioned L2 classes with native speakers, L2 coursework or methods employed inside the classroom, and instructional policies and attitudes. While only one participant attributed demotivation to internal factors, notably pressures of setting standards too high. This implies that external factors are a great source of demotivators for students.

The last and fourth question was concerned with motivational strategies which Ushioda (1998) divided into four strategies: the first strategy deals with incentives or pressures. More precisely, the incentives refer to spending a year in France or travelling to USA in summer holiday as a reward, while pressures refer to fear of failure or the guilt of wasting parents' money. The second strategy puts much weight on the L2 study by organizing oneself to have work completed in time. The third strategy involves seeking temporary relief from L2 study; for example, having a break or trying to hold conversations with L2 speakers. The fourth strategy is concerned with motivational problems which can be via promoting oneself or talking to classmates and other students about feeling.

To wrap up, Muhonen (2004) stated that "it might be questionable to generalize Ushioda's findings because it was a small-scale study. On the other hand, the purpose of the study was not to undermine previous quantitative research on motivation but to refer an alternative way of exploring motivation."

\section{Oxford (1998)}

Oxford (1998) conducted a content analysis on 250 students, from both high schools and universities, who were asked to write essays about their learning experience in a period of five years. They were asked several questions such as 'Describe a situation in which you experienced conflict with a teacher' and 'Talk about a classroom in which you felt uncomfortable.' As a result of this study, Oxford (1998) found four most important demotivating factors which are as follows:

- the teacher's personal relationship with the students;

- the teacher's attitude towards the course or the material;

- $\quad$ style conflicts between teachers and students; and

- the nature of the classroom activities.

Similarly to previous studies, the majority of the 250 students included in this content analysis described teachers as the 
most demotivating factor. This result contains two points: the first one is that teachers need to be aware that students' psychology, negative attitudes towards L2, and society are not the only source of demotivation for students, but teachers themselves are on the top of the demotivating factors' list. The second point is that students, as it was stated before, usually attribute motivation to themselves and demotivation to their teachers.

The main flaw that can be clearly remarked from Oxford's (1998) study is its primary focus on one demotivating factor, namely the teacher. The prompts used by Oxford (1998) had an influence on the students' answers about demotivation. In other words, the way the prompts were used led the students to direct their opinion to teacher to be a main source of demotivation. A case in point is the question 'Describe a situation in which you experienced conflict with a teacher' which surely affected the participants' answers, because all of them approximately had a conflict with their teacher before, so they reported it in this study and was considered a demotive related to teachers. But the question is 'Which one is responsible for that conflict? Is it the students or the teachers?' Despite the flaws that were raised in Oxford' (1998) study, it is still one of the most credible studies that have been carried out on demotivation so far.

\section{Dörnyei (1998)}

Unlike chambers (1993), Ushioda (1998), and Oxford (1998) who carried out their studies without investigating in advance whether their participants were demotivated or not, Dörnyei (1998) conducted a very precise study on demotivation. That is to say, he included only those students who were claimed by their teachers to be demotivated in L2 learning,

Similarly to Ushioda (1998), Dörnyei (1998) followed a qualitative approach. He involved 50 L2 students from different Budapest's high schools, who were studying either German or English as FLs. Data was gathered via a 10 to 30 minute structured interview with giving more freedom to students to talk about their demotivating factors towards L2 learning. Consequently, Dörnyei (1998) came up with nine different categories of demotivators and are presented in Table 1 below.

Similarly to the previous studies carried out by Chambers (1993), Ushioda (1998), oxford (1998), and Dörnyei (1998) found that teacher was the main demotivator in language learning with a percentage of $40 \%$. This does ensure that teacher is still the greatest source of demotivation for students, not only in language learning but in learning in general as it was stated by both Zhang (2007) and Gorham \& Christophel (1992). Moreover, teacher was revealed to be the most frequent demotive not only in one culture, but in several ones as well. In other words, the four studies included here were conducted in many countries around the world, and all of them discovered that teacher was the demotive that the majority of students suffered from. The conclusion drawn from these studies contains an implicit message directed towards teachers, who need to modify the way they behave and treat their students via strengthening their relationship and treating them with more respect and equality, taking into serious consideration their methods of teaching.

\section{METHODOLOGY}

\section{Setting and Participants}

This study was conducted in 6 Moroccan secondary schools. The participants of this study were 201 baccalaureate students (second year) who were represented by 84 males and 117 females. The participants' age ranged from 16 to 18 years. This study adopted a non-probability sampling technique, namely the convenience sampling.

\section{Instruments}

\section{Questionnaire}

The questionnaire employed in the study was composed of 23 items. The questionnaire covered four sections which aimed at investigating students and the four demotivating factors in ELL. Section One included 5 items and dealt with students' perception for ELL. Section Two included 7 items and it was concerned with English and demotivation. Section Three involved 6 items and referred to teacher of English and demotivation. Section Four comprised 5 items and it was about learning environment and demotivation. The questionnaire was administered in the Arabic language as the level of baccalaureate students in English did not allow them to understand this instrument properly which may have negatively affect the answers and the results of the present study. This questionnaire showed an internal consistency of 0.92 based on Cronbach's coefficient alpha, whereas a test-retest reliability indicated $r=0.83(p<.01)$. This strongly means that this was a valid and reliable instrument.

\section{Writing test}

After filling out the questionnaire, the 210 students who participated in the study were asked to write a paragraph in the Arabic language on the following topic: "According to your own experience during learning the English language, what are the factors that demotivated you in learning this language?" This instrument was employed in order to give answers to the fifth and sixth RQs.

This instrument was chosen for three main reasons: first, as the questionnaire was mainly based on closed items, I wanted to give freedom to the participants to express their own opinions and mention what factors demotivated them while learning English. Second, Oxford (1998) administered a writing test to her participants, and she came up with one of the most reliable research that has been written on L2 demotivation. Third, the aim behind choosing a writing test and not an interview was that students needed time to recall demotivating incidents and factors, so the immediacy of the interview method may not have been the most effective technique for gathering clearly presented personal experiences.

\section{Procedures}

After the administration of the two scales, instructions on the objective of the study and on how to fill out the questionnaire were told to the participants. The participants were informed that there was no right or wrong answer, that their 
Table 1. Categories of demotivating factors

\begin{tabular}{|c|c|c|}
\hline & Demotivators & Examples \\
\hline 1 & Teacher $(40 \%)$ & Teacher's personality, competence, and commitment. \\
\hline 2 & Reduced self-confidence (15\%) & Experience of failure, and teacher \\
\hline 3 & Inadequate school facilities & $\begin{array}{l}\text { Group is too big, changing teachers, and not being on } \\
\text { similar level. }\end{array}$ \\
\hline 4 & Negative attitudes towards the L2 & Grammar of the L2 and the way it sounds \\
\hline 5 & The compulsory nature of the L2 study & $\begin{array}{l}\text { Being obliged to learn English for its importance } \\
\text { over another L2. }\end{array}$ \\
\hline 6 & Inference of another FL being studied & $\begin{array}{l}\text { Studying both German and English as two FLs in the } \\
\text { same grade. }\end{array}$ \\
\hline 7 & Negative attitudes towards the L2 community & American culture is not attractive. \\
\hline 8 & Attitudes of group members & $\begin{array}{l}\text { Students who laugh at other students make them } \\
\text { embarrassed. }\end{array}$ \\
\hline 9 & Coursework & Very bad \\
\hline
\end{tabular}

confidentiality would be kept secured, and that their answers would be used for the study only. Moreover, any questions that might seem vague, to any participant, were explained.

\section{Data Analysis}

As this study was based on descriptive research, it was recommended to use quantitative statistical procedures. In other words, both the questionnaire and the writing test were analyzed quantitatively by SPSS version 17 . The latter provided the statistical techniques which were recommended for giving answers to the RQs: frequency distribution and percentages, Cross-tabulation, Chi-Square Tests, and Independent Samples t-Test. Despite the qualitative nature of the writing test, it was also analyzed quantitatively by counting the number of demotivating factors mentioned by the respondents. The demotivating factors were classified into four categories just like those included in the questionnaire with the exception of the student category, because no one of the respondents claimed to be a demotivating factor him/herself. Hence, the four categories that were used are 'English language,' 'Teacher of English,' 'Learning environment,' and 'Others.' The latter category included those demotivators which could not be coded in the three other categories. Besides, the statistical significance was set on the level of.05 (95\%) for all statistical procedures.

\section{RESULTS AND DISCUSSION}

\section{Students' Perception for ELL}

The first RQ that was addressed in this study was covered by Section One in the questionnaire: "Do students perceive themselves positively in ELL?" According to the data obtained by the 5 questions asked by this section, it is illustrated that most of the respondents were more positive in answering those questions. It is revealed that a considerably high number, $80.2 \%$, of the participants claimed that they were very good or good or average students. Besides, a significant number of students, $59.7 \%$, stated that they were not neglected by their teachers of English in the classroom. This means that the majority felt comfortable while learning English. More than half of the students, $57.2 \%$, also pointed out that they were not responsible for their demotivation, which highly backs up the study conducted by Kearney et al. (1991), and Gorham and Christophel (1992) who found that most students attributed their demotivation to teachers while they attributed motivation and desire to know to themselves. Simply put, demotivation is a teacher-owned problem. The conclusion that may be drawn from these results is that most of the students had a positive perception towards themselves in learning English. However, whether this positive perception really takes place in real life or not, the question is still open to be investigated by psychologists.

\section{English Language and Demotivation}

Section Two was designed to address the second RQ: "Do students regard English as a demotivator?" In a comparison that was made between students who claimed English to be a very difficult or difficult language and those who claimed it to be easy or very easy, it is indicated that the latter students' number was higher as they were represented by $34.8 \%$ while the others were only $13.4 \%$. However, the majority, $47.8 \%$, referred to English as an average language. This is highly supported by another result in this study which demonstrates that $74.6 \%$ expressed that they did not have a negative attitude towards English. A plausible explanation that might be given to these results is that many Moroccan students nowadays do extra courses at English language centers, which helps them improve their skills in this language and therefore see it as easy. Another explanation is that the majority of Moroccan students are influenced by the American culture, and since English language is a crucial element of that culture, they may not have a negative attitude towards it. This result is consistent with Hirvonen's (2010) assumption who stated that the negative attitudes that Finnish students had towards English, which were due to perceiving the grammar and pronunciation of English as difficult, were not influential in that study. This signifies that both Finnish students, 
in Hirvonen's (2010) study, and Moroccan students, in the present study, had more positive attitudes towards English.

Section two also shows that in terms of English language skills, it is revealed that speaking was reported to be the most difficult skill with a total of $46.8 \%$. This seems a reasonable result, as the speaking skill was approximately absent in the Moroccan curriculum, which automatically generated students who were very weak in this skill and, therefore, considered it the most difficult one. On the opposite, reading skill was found to be the easiest one in English language as it was reported by $45.3 \%$. This is also a logical finding, because the Moroccan curriculum puts much weight on this skill in all languages including English, which enables students to sharpen this skill from the very beginning. The nature of this skill is also another factor that makes it seem easy, as it does not require a hard effort to be developed in comparison with the other skills which take much time to be sharpened, namely speaking, listening, and writing. Moreover, cross-tabulation was conducted to see whether there were any contradictions from the participants. That is to say, whether there were some participants who, for example, referred to the speaking skill as both the most difficult and the easiest skill. Cross-tabulation shows that only $6.4 \%$ of those who stated speaking to be the most difficult skill stated the same skill to be the easiest one, and no one of those who reported reading to be the easiest skill reported it to be the most difficult one. A chi-square test of independence indicates that $\chi^{2}(16, N=201)=117.69, \mathrm{p}<.05$, which means that the relation between the answers given to the two questions was significant and, therefore, there was dependence between them. Generally, it may be concluded that the productive skills (speaking and writing) were more difficult than the receptive skills (reading and listening).

The results for this section demonstrate that a highly overwhelming number of students, $90 \%$, agreed on the importance of English language in the school curriculum. This may be due to the significant role that this language plays in several fields across the world such as media, technology, tourism, politics and so on. That is why $49.8 \%$ of the participants mentioned that English was the FL that they preferred the most, even though French is of paramount importance in the majority of job sectors in Morocco. This clarifies that the students were aware of the importance of FLs just like what was discovered in Chambers' (1993) study, who reported that most of pupils claimed that learning an FL was important or quite important.

Taking what is mentioned above into consideration, it seems logical to find that most of the students, $66.7 \%$, did not consider English to be a demotivating factor to learn it itself, and only a minority, $18.4 \%$, claimed the opposite. Furthermore, cross-tabulation emphasizes that there was a relation between those who considered English as either easy or very easy and those who did not consider the language to be a demotivator and vice versa. A chi-square test of independence also reveals a significant relation, $\chi^{2}(18, N=201)=44.67$, $\mathrm{p}<.05$. In sum, one may conclude for this RQ that the majority of the students did not view English as a demotivator, which means that they may have had a strong will to learn this language.

\section{Teacher of English and Demotivation in ELL}

As for the third RQ: "Do students have a positive attitude towards their teachers of English?" The results of Section Three, which was wholly devoted to this RQ, reveal that a significant number of students, $64.2 \%$, answered that their teachers of English were either very competent or competent. It was also found that $48 \%$ claimed that their teachers' way of teaching was either very good or good. Cross-tabulation was drawn to examine whether there was a relation between competence and teaching methodology. Consequently, $96.2 \%$ of those who claimed that their teachers used a very good way of teaching stated that their teachers were very competent. This may imply that there was a relation between competence and teaching methodology. This signifies that the teacher's methodology is an important element that makes students classify him/her as competent or not. A chisquare test of independence backs up this relation as it shows that $\chi^{2}(25, N=201)=266.84, \mathrm{p}<.05$, which indicates a significant relation.

Moreover, the findings show that many students, $45.6 \%$, strongly agreed or agreed on the fact that they had a strong relation with their teacher of English. This may serve as an indication that teachers of English are more open towards their students and give them more freedom inside the classroom. Taking also into consideration that many teachers of English in Morocco, nowadays, are young and not much older than their students, which results in more understanding of their students' psychology. These factors really strengthen the relationship between students and their teacher. The results, as well, indicate that $60.7 \%$ reported that they did not regard their teacher of English as a demotivator, which means that the majority did not consider the teacher as a problem that may have a negative effect on their learning of the language. This, again, ensures the strong relationship that exists between students and their teachers.

Furthermore, the statement which reported that teacher of English was offensive received both strong disagreement and disagreement by $62.6 \%$, which represented a large number of students. However, to detect whether there was a relation or not between teacher's offensive behavior and his/her contribution to demotivation, cross-tabulation indicates that among those who stated that their teacher did not demotivate them in learning English, 41\% and 35.2\% respectively strongly disagreed and disagreed that their teacher was offensive. This is ensured by a significant relation that is indicated by a chi-square test of independence which shows that $\chi^{2}(15, N=201)=100.57, \mathrm{p}<.05$. In other words, it may be retained from this relation that offensiveness was a negative element that was usually attributed to demotivating teachers. Hence, it may be concluded that the majority of students were highly positive towards their teachers of English.

\section{Learning Environment and Demotivation}

The last section of the questionnaire, Section Four, was devoted to answering the fourth RQ: "Are crowded classrooms the main demotivators in learning environment?" The findings indicate that $66.7 \%$ of the students claimed that they were 
not negatively affected by their classmates while learning English. This may be given several explanations: There was less discomfort among classmates' behaviors, students were more disciplined and may have been more controlled according to the assessment system as they gave much importance to their achievement. In addition, the results show that more than half of the participants, $57.2 \%$, reported that they either strongly disagreed or disagreed with the fact that the textbook of English used by their teachers was complicated, which means that they did not have a negative view towards the textbooks of English. This may serve as an indication that the textbooks of English used in Morocco are largely accepted by students, as they are fully designed by Moroccan textbook designers who are more aware of what Moroccan students need, which strengthens the relation between the textbook and students. Thus, it may be claimed that neither classmates nor textbooks of English were the main demotivating factors in the learning environment.

Besides, it is revealed that many students, $36.8 \%$, considered their classroom atmosphere to be either very active or active. Even though the number was not significantly high, it represented the majority of the students. This result could be interpreted to mean that classroom activities and teaching/learning styles may have been properly used by the teacher, which created a pleasant and a supportive learning environment. Additionally, cross-tabulation clearly clarifies that there was a relation between teaching methodology followed by teacher and the classroom's active atmosphere. As a case in point, it was found that within those who claimed that their classroom was active, $71.4 \%$ pointed out that their teacher methodology was either very good or good. This relationship is emphasized by a chi-square test of independence which indicates that $\chi^{2}(30, N=201)=110.09, \mathrm{p}<.05$, and it refers to a significant relation. Nevertheless, it may not be reasonable to perceive that classroom atmosphere was the main demotivator in the learning environment.

In comparison with what is mentioned for the learning environment, it is obvious that a crowded classroom was considered by the majority of students to be a demotivating factor in ELL. In other words, 70.7\% strongly agreed and agreed on the fact that a crowded classroom negatively affected their learning of English. This result was really expected because an overwhelming majority of secondary schools across Morocco have very crowded classrooms, this is applicable to those included in this study with the exception of only one secondary school. Many plausible explanations may be given to this finding: First, a big classroom does not allow the teacher to pay attention to all students and, therefore, provides those who need extra help whenever they need it. Second, a lot of discipline problems appear which usually distract the attention of both students and teacher. Third, only a very few number of students have the opportunity to participate and express themselves inside the classroom. Fourth, a crowded classroom usually leads to less individualized interaction between students and their teacher, many behavior problems, unimproved students achievement, and lower score exams. These are just some negative consequences that are usually caused by crowded classrooms. This result is consistent with what was stated by
Chambers (1993) who mentioned that some students criticized class-size as a crucial factor of language learning, they stated that they could not learn German because the classroom was crowded and that they needed a bigger one.

Thus, as for the result, it appears that crowded classroom was the only element of learning environment among classmates, textbook of English, and classroom atmosphere which had a consensus, $70.7 \%$, that it was the most negative factor in English learning. Accordingly, it may be concluded that the main demotivating factor in learning environment was crowded classroom. The last result that was given by the questionnaire concludes that the learning environment was the most demotivating factor compared to student him/herself, English language, and teacher of English.

\section{The Students' Main Demotivating Factor}

The writing test included in this study was used to answer the fifth and sixth RQs. Concerning the fifth RQ: "What is the main demotivating factor in ELL?" It was found that most of the demotivators reported by the respondents, $38 \%$, belonged to the learning environment. This result is highly confirmed by the last result given by the questionnaire, which shows that learning environment was, as well, indicated to be the most demotivating factor as it was reported by $56 \%$ of the participants. This result may be a reflection of the bad learning environment that most of Moroccan schools suffer from. To illustrate, the classrooms in secondary schools are usually in bad situations as they lack the simplest thing that a normal classroom should contain, such as clean blackboards, good tables, and painted walls. Classrooms usually contain too many students which results in a very poor atmosphere that contributes to demotivating students. Some students mentioned that they were demotivated by the administration of their school, this may have been due to the bad way the staff treated students. There is almost a complete absence of ICT (Information and Communication Technologies) and libraries within schools, which really play a crucial role in learning in general and learning English in particular. Besides, according to the demotivators mentioned by the students, it appears that the number of external demotivating factors exceeded the internal ones, which suggests that the former demotivators extremely affected students. This seems to be consistent with previous studies which indicated that students were highly influenced by external factors during language learning (Ushioda, 1998; Thi Thu Trang and Baldauf Jr., 2007).

However, it may be claimed that the main demotivating factor in learning English was the learning environment. This conclusion made for this RQ was unexpected, as it was believed that the main demotivating factor would be the teacher, just as it was discovered by Gorham and Christophel (1992), Chambers (1993), Ushioda (1998), Dörnyei (1998), Muhonen (2004), Zhang (2007), Thi Thu Trang and Baldauf Jr. (2007). Accordingly, the reasonable explanation that may be given to this unexpected result, in terms of the main demotivating factor, is that the previous studies took place in countries where the learning environment was highly equipped with facilities and good staff. This might have 
not led students, in those countries, to attribute their main demotivator to the learning environment. On the opposite, the learning environment in the Moroccan context is usually a poor one, which rendered the students to consider it the main demotivating factor. This may be interpreted that there are differences between countries concerning demotivating factors in learning in general and in ELL in particular.

\section{Males and Females' Demotivating Factors}

Concerning the sixth RQ: "Is there a significant difference in the perceived frequency of demotivators among males and females?" An independent sample $t$-test reveals that males $(\mathrm{M}=2.94, \mathrm{SD}=1.063)$ and females $(\mathrm{M}=3.32, \mathrm{SD}=1.248)$; $t(66)=-1.368, \mathrm{p}=0.17$. This result means that there was no difference between males and females in terms of the frequency of demotivating factors that were mentioned in the writing test. This might suggest that gender did not make any difference concerning the number of demotivators that students suffered from. This means that both males and females encountered the same number of demotivators while learning the English language.

\section{CONCLUSION AND IMPLICATIONS OF THE STUDY}

The objective behind conducting this study was to investigate the problem of demotivation in ELL among Moroccan students. According to the results found in this study, a number of demotivating factors stood as an obstacle in the English language classroom and, therefore, made the process of learning that language more difficult. This means that demotivation in ELL is a serious problem in the Moroccan context. It is an issue that needs to be both clearly investigated and given a close attention. Several implications can be raised from the findings of this study and are as follows:

First, on the basis of the results indicated by the study, speaking followed by listening were reported to be the most difficult language skills, the majority of students were weak in these two skills. This suggests that much weight has to be put on speaking and listening. This also indicates that importance has to be given to communicative competence of the students rather than only focusing on grammar and reading comprehension. Besides, the two skills have to be similarly taken into consideration concerning the final grades, instead of evaluating only grammar, reading comprehension, and writing. In other words, all the four language skills have to be given equal significance and no one should be given importance at the cost of the other skills. By all these means, English teaching would give more balance to the process of English learning and, therefore, encourage more students to learn this language. The same problem was found in the Turkish context when Ozsevik (2010) stated that "more research should be conducted on how to assess learners' listening and speaking skills in the Turkish context...From this perspective, students' communicative abilities can be more effectively represented in the selection and placement instruments."

Second, another implication of the study is that English has to be given more importance as the findings indicated that the participants expressed both large consensus concerning the importance of English in the Moroccan curriculum, and a great preference towards English in comparison with the other three languages (French, Spanish, and German). The implication that emanates from these findings is that the importance given to English language in the Moroccan context is not enough. Hence, it has to be increased in a way similar to French language. In other words, English language should be included at the early stages in the Moroccan primary schools, and should be dealt with equally just as it is the situation in private schools. Besides, the Moroccan media needs to incorporate this language by, for example, publishing newspapers and broadcasting programs in the English language so as to better familiarize Moroccans in general and students in particular with this language.

Third, as it was indicated that there were a relationship between considering teacher as a demotivating factor and teacher's offensive behavior, teachers should pay a close attention to this negative misbehavior which is, according to students, a teacher misbehavior that leads many of them not to learn English. This implies that teachers in general and teachers of English language in particular should work on this problem and do their best to eradicate this negative behavior. Furthermore, offensive teachers have to be seriously dealt with both by the school's administration and the government, as they constitute a grave danger in the Moroccan education, and it was reported that many students dropped out of school because their teachers were offensive. However, this problem is not restricted to the Moroccan context, Zhang (2007) claimed that "Even though teacher misbehaviors are infrequent across cultures, their destructive effects on student motivation suggest that teachers should avoid or reduce the occurrence. Teacher misbehavior is not a problem unique to a particular culture; rather it is a universal problem facing the global community of educators."

Fourth, in the light of the results reported by the study, many students referred to English classroom as either boring or very boring, which implies that it is an issue that has to be paid a close attention. The present study indicates also that there was a relation between classroom atmosphere and teacher methodology. In order to eradicate this problem, or at least reduce it, teachers should get rid of those conventional method of teaching, as they are no longer suitable for current students. That is to say, teachers should update their ways of delivering knowledge to students by reading and being aware of those new teaching methods so as to add a flavor to the classroom atmosphere and, therefore, make it more active. Additionally, the Moroccan government should organize trainings for teachers of English so as to keep them in touch with all what is new in the field of ELT rather than relying on old fashioned teaching methods.

Fifth, in this study, crowded classroom was revealed to be an extremely disrupting demotivator. In other words, an overwhelming number of students expressed that they highly suffered from this factor. Nowadays, most of Moroccan schools encounter this heavy problem as classrooms contain a high number of students which ranges from 40 to 50 persons. This surely has a deeply negative effect on learning in general and English learning in particular. To put it differently, 
good English classrooms need to give opportunity to all students to participate and communicate, but crowded classrooms deprive learners of a lot of activities that play a constructive role in developing their English language skills. This calls for an urgent solution that should be found by the Moroccan government. This could be through building enough schools and training more teachers so as to close this large gap.

Sixth, in contrast with previous studies conducted on demotivation, the present study reveals that the main demotivating factor in English learning was the learning environment. This signifies that much weight has to be put on the latter factor as it is the place where students receive knowledge from their teachers. This also means that learning environment has to be equipped with all the means that make the process of both ELT and ELL much easier. As a case in point, the Moroccan government needs to equip English classrooms with all facilities that a modern classroom requires. The staff of the administration, as well, should create a good relation with students as it was mentioned to be among those demotivators in learning environment. By these means, learners would be put in a suitable atmosphere that encourages them to learn English language in particular and other subjects in general.

Last, in his famous study, chambers (1993) came up with 6 pieces of advice that L2 and FL teachers have to take into serious consideration:

1. the stereotypical pupil, be s/he demotivated or not, does not exist; all pupils have different needs, interests, likes and dislikes; you cannot please them all, all of time;

2. pupils identified as demotivated do not want to be ignored or given up as a bad job; in spite of their behaviour, they want to be encouraged;

3. demotivated pupils often have very low self-esteem; they need to be praised for what they can do and what they are good at; they need and often crave attention;

4. their opinions are of value; they should be asked what they think;

5. they need a carrot to be dangled in front of them - not a GCSE certificate two years hence but something for now;

6. with some pupils it will appear that nothing works; do not despair - the problem is often not with learning languages, it is with learning; we need to adjust the attitude of parents, friends and society before real success can be achieved.

\section{REFERENCES}

Addison, R., \& Brundrett, M.(2008). Motivation and demotivation of teachers in primary schools: The challenge of change. Education, 36, 79 - 94.

Arai, K. (2004). What 'demotivates' language learners?: qualitative study on demotivational factors and learners' reactions. Bulletin of Toyo Gakuen University, 12, 39-47.

Brown, H.D. (1987). Principles of language learning and teaching. USA: Englewood Cliffs, NJ: Prentice Hall.

Callaghan, M. (1998). An investigation into the causes of boys' underachievement in French, Language Learning Journal 17, 2-7.
Chambers, G. (1993). Taking the 'de' out of demotivation. Language Learning Journal, 7, 13-16.

Chambers, G. (1999). Motivating language learners. Clevedon: Multilingual Matters.

Chomsky, N. (1959). A review of B.F. Skinner's Verbal Behavior. Language, 35, 26-58.

Chomsky, N. (1968). Language and Mind. New York: Hartcourt Brace Jovanovich.

Christophel, D. M., \& Gorham, J. (1995). A test-retest analysis of student motivation, teacher immediacy, and perceived sources of motivation and demotivation in college classes. Communication Education, 44, 292 - 306.

Cook, V. (1991). Second language learning and language teaching. London: Edward Arnold.

Deci, E.L., \& Ryan, R.M. (1985). Intrinsic motivation and self-determination in human behavior. New York: Plenum.

Dörnyei, Z. (1990). Conceptualizing motivation in foreign language learning. Language Learning, 40, 45-78.

Dörnyei, Z. (1994). Motivation and motivating in the foreign language classroom. The Modern Language Journal, $78,273-284$.

Dörnyei, Z. (1998) Demotivation in foreign language learning. Paper presented at the TESOL' 98 Congress, Seattle, WA. March.

Dörnyei, Z. (2001). Teaching and Researching Motivation. Harlow, England: Longman.

Dörnyei, Z. (2003). Questionnaires in second language research. London: Lawrence Erlbaum Associates.

Ellis, R. (2000). Second Language Acquisition. New York: Oxford University Press.

Fromkin, V., \& Rodman, R. (1993). An introduction to language. USA: Harcourt Brace College Publishers.

Gardner, R. C. (1985). Social psychology and second language learning: The role of attitudes and motivation. London: Edward Arnold.

Gardner, R.C., \& Lambert, W.E. (1959). Motivational variables in second language acquisition. Canadian Journal Of Psychology, 13, 266-272.

Gorham, J. (1988). The relationship between verbal teacher immediacy behaviors and student learning. Communication Education, 37, 40-53.

Gorham, J. \& Christophel, D. M. (1992). Students' perceptions of teacher behaviors as motivating and demotivating factors in college classes. Communication Quarterly, 40, 239-252.

Gorham, J., \& Millette, D. M. (1997). A comparative analysis of teacher and student perceptions of sources of motivation and demotivation in college classes. Communication Education, 46, 245 - 261.

Hall, E. T. (1976). Beyond culture. New York: Anchor Books. Halliday, M.A.K. (1975) Learning How to Mean. London: Edward Arnold.

Hargreaves, D. (1972). Interpersonal relations in education. London: Routledge and Kegan Paul.

Hasegawa, A. (2004). Student demotivation in the foreign language classroom. Takushoku Language Studies, 107, 119-36.

Hilgard, E.R., \& Bower, G.H. (1966). Theories of learning. New York: Appleton-Century-Crofts. 
Hirvonen, J. (2010). Demotivation in learning English among immigrant pupils in the ninth grade of comprehensive school. Unpublished Pro Gradu Thesis. University of Jyväskylä, Department of Languages.

Ho, M. C. (1998). Culture studies and motivation in foreign and second language learning in Taiwan. Language, Culture and Curriculum, 11, $165-182$.

Hockett, C. F. (1967). A course in modern linguistics. New York: The Macmillan Company and Canada.

Hofstede, G. (1980). Culture's consequences: International differences in work-related values. Beverly Hills, CA: Sage.

Hymes, D. (1972). On Communicative Competence. In J. B. Pride and J. Holmes (eds). Sociolingguistics. Harmondsworth: Penguin.

Kearney, P., Plax, T. C., \& Burroughs, N. F. (1991). An attributional analysis of college students' resistance decisions. Communication Education, 40, 325-342.

Kiziltepe, Z. (2008). Motivation and demotivation of university teachers. Teachers and Teaching, 14, 515 -530.

Koiso, K (2003). The characteristics of motivation of Japanese adult English learners. General Social Surveys [5] JGSS from JGSS-2003 Data. Retrieved November 26, 2008fromhttp://jgss.daishodai.ac.jp/japanese/5research/ monographs/jgssm5pdf/jgssm5_8.pdf.

Larsen-Freeman, D. (2000). Techniques and principles in language teaching. Oxford: Oxford University Press.

Logan, F. A. (1970). Fundamentals of learning and motivation. Dubuque, IA: William C. Brown.

Mitchell, R., \& Myles, F. (1998). Second Language Theories. Arnold, London.

Muhonen, J. (2004). Second language demotivation: factors that discourage pupils from learning the English language. Unpublished Pro Gradu Thesis. University of Jyväskylä, Department of Languages.

Nash, R. (1976). Teacher expectations and pupil learning. London: Routledge and Kegan Paul.

Oxford, R. L. (1998). The unravelling tapestry: teacher and course characteristics associated with demotivation in the language classroom. Demotivation in foreign language learning. Paper presented at the TESOL '98 Congress,
Seattle, WA, March. In Dörnyei, Z. (2001). Teaching and researching motivation. Harlow: Longman.

Oxford, R., \& Shearin, J. (1994). Language learning motivation: Expanding the theoretical framework. The Modern Language Journal. 78, 12-28.

Ozsevik, Z. (2010). The use of communicative language teaching(CLT): TurkishEFL teachers' perceived difficulties in implementing CLT in Turkey.Unpublished Thesis. University of Illinois at Urbana-Champaign.

Pidgeon, D. (1970). Expectation and pupil performance. Slough: NFER.

Purkey, W. W. (1970). Self-concept and school achievement. Englewood Cliffs, NJ: Prentice-Hall.

Richards, J., \& Rodgers, T. (1989). Approaches and Methods in Language Teaching.

Cambridge: Cambridge University Press.

Sapir, E. 1921. Language: An introduction to the study of speech. New York: Harcourt, Brace and company.

Schunk, D. H. (1985). Self-efficacy and classroom learning. Psychology in the Schools, 22, 208-223.

Selinger, H. W., \& Shohamy, E. (1989). Second language research methods. Hong Kong: Oxford University Press.

Spolsky, B. (1989). Conditions for Second Language Learning. Oxford: Oxford University Press.

Thi Thu Trang, T. \& Baldauf Jr. R.B. (2007). Demotivation: understanding the resistance to English language learning - the case of Vietnamese students. The Journal of Asia TEFL, 4, 79-105.

Trudgill,P. (1983). Sociolinguistics: An introduction to language and society. Harmondsworth, Middlesex, England: Penguin Books.

Widdowson, H.G. (1978). Teaching language as communication. Oxford: Oxford University Press.

Williams, M., \& Burden, L. R. (1997). Psychology for language teachers: a social constructivist approach. Cambridge: Cambridge University Press.

Zhang, Q. (2007). Teacher misbehaviors as learning demotivators in college classrooms: A cross-cultural investigation in China, Germany, Japan, and the United States. Communication Education, 56, 209-227. 